\title{
A!
}

This is an electronic reprint of the original article.

This reprint may differ from the original in pagination and typographic detail.

Koppinen, Jussi; Kukkola, Jarno; Hinkkanen, Marko

\section{Plug-in identification method for an LCL filter of a grid converter}

Published in:

IEEE Transactions on Industrial Electronics

DOI:

10.1109/TIE.2017.2787546

Published: 02/04/2018

Document Version

Peer reviewed version

Please cite the original version:

Koppinen, J., Kukkola, J., \& Hinkkanen, M. (2018). Plug-in identification method for an LCL filter of a grid converter. IEEE Transactions on Industrial Electronics, 65(8), 6270-6280.

https://doi.org/10.1109/TIE.2017.2787546

This material is protected by copyright and other intellectual property rights, and duplication or sale of all or part of any of the repository collections is not permitted, except that material may be duplicated by you for your research use or educational purposes in electronic or print form. You must obtain permission for any other use. Electronic or print copies may not be offered, whether for sale or otherwise to anyone who is not an authorised user. 


\title{
Plug-in Identification Method for an LCL Filter of a Grid Converter
}

\author{
Jussi Koppinen, Jarno Kukkola, and Marko Hinkkanen, Senior Member, IEEE
}

\begin{abstract}
This paper proposes a method for estimating the two inductances and the capacitance of an LCL filter, connected between the converter and the grid. Only the DC-bus voltage and converter phase currents need to be measured. An excitation signal is fed into the converter voltage reference. The fundamental and selected harmonic components are removed from the stored identification data to prevent biases in the parameter estimates. The parameters of the hold-equivalent discrete-time model are estimated recursively. The inductance and capacitance estimates are calculated from the estimated discrete-time parameters using the corresponding closed-form model. The proposed method can be added to existing converter control algorithms. It can provide the parameter estimates for the converter control. Further, it can be run occasionally during the normal operation in order to obtain an updated grid inductance estimate. Experimental results show that the proposed method yields very good parameter estimates and that it can also detect the changes in the grid inductance.
\end{abstract}

Index Terms-Converters, parameter estimation, power filters.

\section{INTRODUCTION}

G RID converters play a key role in the integration of distributed energy sources since they act as an interface between the electric grid and an energy source. There is also a growing trend to replace diode bridges in motor drives with grid converters, which provide a low content of current harmonics and enable braking energy conservation. As a result, the number of grid converters is expected to increase substantially in the future.

An LCL filter, whose equivalent circuit model is shown in Fig. 1, is commonly used between the converter and the grid in order to attenuate the converter switching harmonics. Even if the nominal inductance and capacitance values are typically known through the filter design process [1]-[3], some parameter uncertainties are present due to manufacturing tolerances and ageing phenomena. Moreover, the filter may be connected to the grid via a transformer, whose leakage inductance is unknown. The grid inductance behind the point of common coupling (PCC) is also typically unknown. These unknown inductances can be considered as a part of the gridside inductance in the LCL filter model. Naturally, an LC filter

This work was supported in part by ABB Oy.

J. Koppinen and M. Hinkkanen are with the Department of Electrical Engineering and Automation, Aalto University, Espoo, Finland (e-mail: jussi.koppinen@aalto.fi; marko.hinkkanen@aalto.fi).

J. Kukkola is with ABB Oy Drives, Helsinki, Finland (e-mail: jarno.kukkola@fi.abb.com).

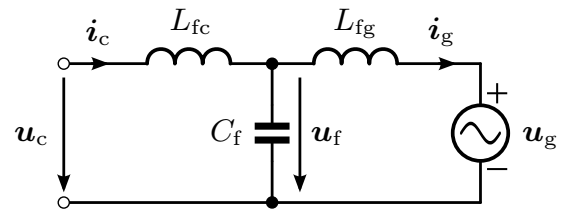

Fig. 1. Space-vector circuit model of an LCL filter connected to the grid.

connected to the inductive grid can be modelled using Fig. 1 as well.

Grid converters are often controlled using model-based control methods, e.g., [4]-[9], whose controller gains are calculated as a function of the LCL filter parameters. Then, trial and error in the control tuning stage can be avoided. If the filter parameters could be automatically identified with good accuracy, the start-up process of the converter could be simplified and the control performance could be improved. Furthermore, the identified parameters could be beneficial for condition monitoring and fault diagnosis purposes.

Various methods have been proposed for estimating the grid impedance: nonparametric frequency-response based methods [10]-[17] and parametric model-based methods [18]-[27]. The nonparametric methods estimate the frequency response while the parametric methods estimate the parameters of a predefined model, such as an LR or LCL circuit. Some methods aim to estimate the grid impedance behind a known L filter [18][21], [26] or behind a known LCL filter [11]-[17], [22]-[27]. In [16], [19], model parameters are estimated without a grid connection. There are also adaptive control methods that take the variation in the grid inductance [28], [29] or in the grid frequency [30] into account.

The estimation can be performed noninvasively [18], [21], [24], [27], but the signal-to-noise ratio might be poor, leading to inaccurate parameter estimates. The estimation accuracy can be improved by using an excitation signal, such as step [19], [20], sinusoid [12], sine sweep [10], multi-sine [11], impulse [13], [15], [25], [26], resonance [22], discrete interval binary sequence [17], and pseudo-random binary sequence (PRBS) [14], [16]. The PRBS is a good choice for LCL filter identification: it can be easily generated, it has a wide power spectrum, and its amplitude is constant [31], [32].

The methods in [33]-[36] aim to identify the whole LCL filter. A discrete-time state-space model is identified in [33], [34], but no experimental results are provided. In [35], the frequency response of the LCL filter was measured for testing the system stability. The method requires the measurements of the DC-bus voltage, converter currents, grid currents, and grid 
Plug-in identification

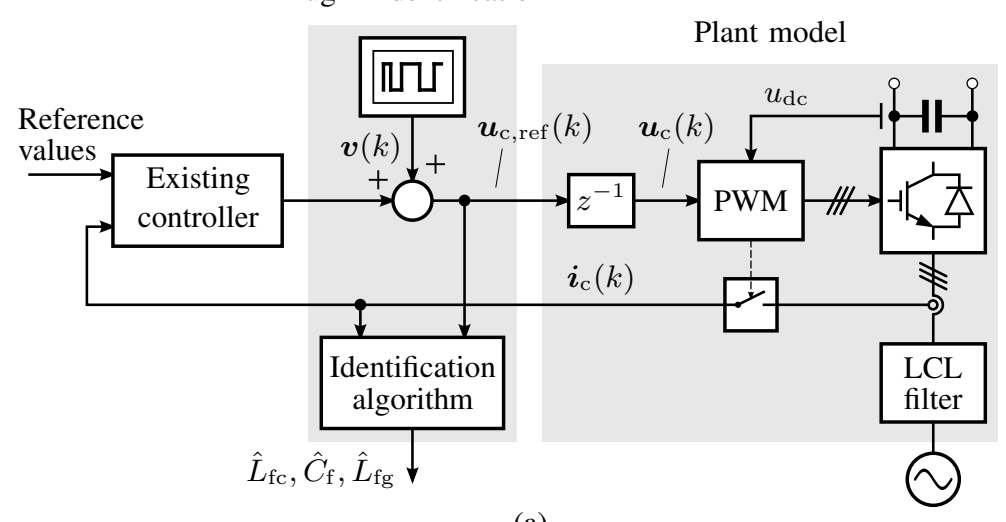

(a)

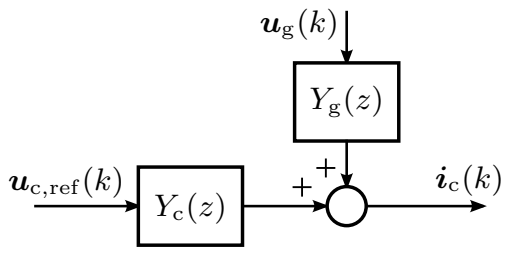

(b)

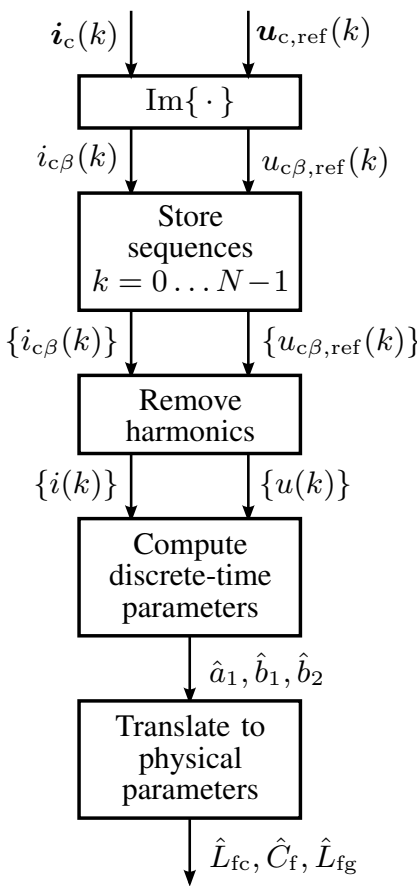

(c)

Fig. 2. (a) Identification setup. The sampling of the converter currents is synchronized with the PWM. The switch block represents the sampler. The computational delay $z^{-1}$ is explicitly shown. The DC-bus voltage $u_{\mathrm{dc}}$ is measured for the PWM, which calculates the duty cycles for the power switches. (b) Discrete-time plant model as seen by the digital control system. (c) Block diagram of the identification algorithm.

voltages. The methods [33]-[35] do not provide the physical parameters (the two inductances and the capacitance) of the LCL filter.

In a preliminary study [36], the physical parameters of the LCL filter were identified. The method uses the PRBS as an excitation signal, injected into the converter reference voltage, and a discrete-time autoregressive moving average with exogenous input (ARMAX) as a model structure. The resulting discrete-time model parameters are translated into the continuous-time physical parameters by comparing the estimated discrete-time model with an exact closed-form discretetime model. The method in [36] can be difficult to use during normal operation, since a proportional current controller has to be used during the identification process. Furthermore, the grid voltage has to be measured, in addition to the DC-bus voltage and the converter phase currents.

In this paper, we propose an enhanced version of [36], with the following improvements:

1) Only the DC-bus voltage and the converter phase currents need to be measured.

2) The method can be used in a plug-in manner with any typical pulse-width modulator (PWM) based converter control system.

3) Before computing the parameters, low-order gridfrequency harmonics are removed from the identification data, making the method more robust against distorted grid voltages.

4) The real-valued arithmetics and recursive algorithms are applied, making the method easier to implement and computationally more efficient.
The proposed method is experimentally verified using a 12.5kVA grid converter setup.

\section{SYSTEM MODEL}

\section{A. Continuous-Time Model}

Fig. 1 shows the space-vector model for an LCL filter, which is connected between the grid converter and the grid. The LCL filter is modeled in stationary coordinates as the converterside inductance $L_{\mathrm{fc}}$, the capacitance $C_{\mathrm{f}}$, and the grid-side inductance $L_{\mathrm{fg}}$. An inductive grid impedance can be included in $L_{\mathrm{fg}}$. Further, if a transformer exists between the LCL filter (or an LC filter) and the grid, the leakage inductance of the transformer can be included in the grid-side inductance $L_{\mathrm{fg}}$.

The converter current can be expressed as

$$
\boldsymbol{i}_{\mathrm{c}}=Y_{\mathrm{c}}^{\prime}(s) \boldsymbol{u}_{\mathrm{c}}+Y_{\mathrm{g}}^{\prime}(s) \boldsymbol{u}_{\mathrm{g}}
$$

where the transfer operators $Y_{\mathrm{c}}^{\prime}(s)$ and $Y_{\mathrm{g}}^{\prime}(s)$ are marked with the prime in order to separate them from their discrete-time counterparts. The transfer operator from the converter voltage $\boldsymbol{u}_{\mathrm{c}}$ to the converter current $\boldsymbol{i}_{\mathrm{c}}$ is

$$
Y_{\mathrm{c}}^{\prime}(s)=\frac{1}{L_{\mathrm{fc}}} \frac{s^{2}+\omega_{\mathrm{z}}^{2}}{s\left(s^{2}+\omega_{\mathrm{p}}^{2}\right)}
$$

where

$$
\omega_{\mathrm{p}}=\sqrt{\frac{L_{\mathrm{fc}}+L_{\mathrm{fg}}}{L_{\mathrm{fc}} L_{\mathrm{fg}} C_{\mathrm{f}}}} \quad \text { and } \quad \omega_{\mathrm{z}}=\sqrt{\frac{1}{L_{\mathrm{fg}} C_{\mathrm{f}}}}
$$

are the resonance and anti-resonance frequencies, respectively. The transfer operator $Y_{\mathrm{g}}^{\prime}(s)$ from the grid voltage $\boldsymbol{u}_{\mathrm{g}}$ to the converter current $\boldsymbol{i}_{\mathrm{c}}$ could be easily derived from Fig. 1 . 


\section{B. Discrete-Time Model}

Fig. 2(a) shows the block diagram of the grid-converter system equipped with an LCL filter. The sampling of the converter current measurement is synchronized to the PWM. Further, the digital control system is assumed to have the onesampling-period time delay due to the finite computation time. Fig. 2(b) illustrates the corresponding hold-equivalent discretetime model (cf. Appendix A). The converter current $\boldsymbol{i}_{\mathrm{c}}(k)$ depends on the converter voltage reference $\boldsymbol{u}_{\mathrm{c}, \text { ref }}(k)$ and the grid voltage $\boldsymbol{u}_{\mathrm{g}}(k)$ according to

$$
\boldsymbol{i}_{\mathrm{c}}(k)=Y_{\mathrm{c}}(z) \boldsymbol{u}_{\mathrm{c}, \text { ref }}(k)+Y_{\mathrm{g}}(z) \boldsymbol{u}_{\mathrm{g}}(k)
$$

where $k$ is the discrete-time index, $z$ is the forward-shift operator, and $Y_{\mathrm{c}}(z)$ and $Y_{\mathrm{g}}(z)$ are the pulse-transfer operators from the converter and grid voltages, respectively, to the converter current. The pulse-transfer operator $Y_{\mathrm{c}}(z)$ can be expressed as

$$
Y_{\mathrm{c}}(z)=\frac{z^{-1}\left(b_{1} z^{-1}+b_{2} z^{-2}+b_{1} z^{-3}\right)}{1+a_{1} z^{-1}-a_{1} z^{-2}-z^{-3}}
$$

where

$$
\begin{aligned}
& a_{1}=-1-2 \cos \left(\omega_{\mathrm{p}} T_{\mathrm{s}}\right) \\
& b_{1}=\frac{T_{\mathrm{s}}+L_{\mathrm{fg}} \sin \left(\omega_{\mathrm{p}} T_{\mathrm{s}}\right) /\left(\omega_{\mathrm{p}} L_{\mathrm{fc}}\right)}{L_{\mathrm{fc}}+L_{\mathrm{fg}}} \\
& b_{2}=-\frac{2 T_{\mathrm{s}} \cos \left(\omega_{\mathrm{p}} T_{\mathrm{s}}\right)+2 L_{\mathrm{fg}} \sin \left(\omega_{\mathrm{p}} T_{\mathrm{s}}\right) /\left(\omega_{\mathrm{p}} L_{\mathrm{fc}}\right)}{L_{\mathrm{fc}}+L_{\mathrm{fg}}}
\end{aligned}
$$

and $T_{\mathrm{s}}$ is the sampling period. The measurement noise is omitted here, but it is taken into account in the parameter identification, as presented in Section III-D.

\section{IDENTification Process}

Fig. 2(a) shows the overall identification setup. The proposed identification method can be added to any typical PWMbased control system in a plug-in manner. Fig. 2(c) shows the block diagram of the identification method. The identification process has four stages: 1) an excitation signal $\boldsymbol{v}$ is fed into the system and the sequences for the identification algorithm are stored; 2) the stored sequences are preprocessed by removing the undesired harmonics; 3) the discrete-time model parameters are computed; 4) the discrete-time parameters are translated into the inductance and capacitance values.

\section{A. Excitation Signal}

For the system identification, an excitation signal $\boldsymbol{v}=$ $v_{\alpha}+\mathrm{j} v_{\beta}$ is superimposed on the voltage reference obtained from the converter control functions, typically from a current controller, cf. Fig. 2. Here, the PRBS is selected since it can be easily implemented using feedback shift registers, resulting in a deterministic and easily repeatable signal, and since it has a wide power spectrum and lowest possible ratio of the peak amplitude to the rms value [31], [32].

The excitation voltage could be fed to the $\alpha$-direction, $\boldsymbol{v}=$ $v_{\alpha}+\mathrm{j} 0$, leading to the converter current response in all the three phases. If the $\beta$-direction is chosen, $\boldsymbol{v}=0+\mathrm{j} v_{\beta}$, the response splits between the b- and c-phase currents, while the a-phase current is ideally unaffected. Here, the $\beta$-direction is chosen. Choosing this direction slightly reduces the effects of the inverter nonlinearities on the PWM accuracy and parameter estimation, since the zero-crossings in the a-phase current are not distorted. On the other hand, the harmonic distortion in the b- and c-phase currents is then higher, since the excitation signal is not split equally to all three phases.

The PRBS amplitude should be high enough in order to excite the desired frequency components in the converter current and to get accurate parameter estimates. However, too high amplitude causes distortions in the grid current. Therefore, a trade-off has to be made between the excitation power and current distortion when selecting the amplitude.

The PRBS is generated at the sampling frequency $f_{\mathrm{s}}=$ $1 / T_{\mathrm{s}}$, giving the half-power point of its power spectrum around $0.4 f_{\mathrm{s}}$. It is worth noticing that the half-power point should be higher than the resonance frequency $\omega_{\mathrm{p}} /(2 \pi)$ of the LCL filter in order to excite the system at the resonance frequency and to get information about the filter capacitor $C_{\mathrm{f}}$. The duration of the PRBS is expressed as $T_{\mathrm{e}}=\left(2^{m}-1\right) T_{\mathrm{s}}$, where $m$ is the number of the shift registers.

\section{B. Data Storing}

Since the PRBS voltage is fed into the $\beta$-direction, only the imaginary components of the converter voltage reference and the measured converter current are needed in the identification process:

$$
u_{\mathrm{c} \beta, \text { ref }}=\operatorname{Im}\left\{\boldsymbol{u}_{\mathrm{c}, \mathrm{ref}}\right\} \quad i_{\mathrm{c} \beta}=\operatorname{Im}\left\{\boldsymbol{i}_{\mathrm{c}}\right\}
$$

Naturally, if the excitation signal were fed into the $\alpha$-direction, the real components would be taken. The $N$-sample sequences

$$
\begin{aligned}
\left\{u_{\mathrm{c} \beta, \text { ref }}(k)\right\} & =\left\{u_{\mathrm{c} \beta, \mathrm{ref}}(0), u_{\mathrm{c} \beta, \mathrm{ref}}(1), \ldots, u_{\mathrm{c} \beta, \mathrm{ref}}(N-1)\right\} \\
\left\{i_{\mathrm{c} \beta}(k)\right\} & =\left\{i_{\mathrm{c} \beta}(0), i_{\mathrm{c} \beta}(1), \ldots, i_{\mathrm{c} \beta}(N-1)\right\}
\end{aligned}
$$

are stored in the memory, while the PRBS voltage is applied. The stored sequences include also the operating-point (gridfrequency harmonic) components and measurement noise, in addition to the PRBS-generated components. In order to be able to easily remove the grid-frequency harmonics, the length $N T_{\mathrm{S}}$ of the sequences should be an integer multiple of the grid period $T_{\mathrm{g}}=2 \pi / \omega_{\mathrm{g}}\left(\right.$ e.g. $\left.N T_{\mathrm{s}}=5 \cdot T_{\mathrm{g}}\right)$. Naturally, the duration $T_{\mathrm{e}}$ of the PRBS should be equal or longer than $N T_{\mathrm{s}}$.

\section{Removing Harmonics}

Ideally, the grid voltage has only the fundamental component at the angular frequency $\omega_{\mathrm{g}}$, which is assumed to be fixed value during identification. In practice, some low-order harmonics (e.g., 5th and 7th) are also present. Furthermore, the power converter produces low-order harmonics due to its nonlinearities (deadtime effect and power-device voltage drops) in addition to the switching harmonics. The same loworder harmonics appear in the converter current as well. These harmonic components cause biases to the parameter estimates during identification. In order to obtain more accurate parameter estimates, the most significant harmonic components should be removed from the stored sequences (8). 
The operating point is assumed to stay constant during the short identification process. The averages $A_{\mathrm{u} 0}$ and $A_{\mathrm{i} 0}$ and the grid-frequency harmonics can be easily removed from the sequences as

$$
\begin{aligned}
& u(k)=u_{\mathrm{c} \beta, \mathrm{ref}}(k)-A_{\mathrm{u} 0}-\sum_{h} A_{\mathrm{u} h} \cos \left(h \omega_{\mathrm{g}} k T_{\mathrm{s}}+\phi_{\mathrm{u} h}\right) \\
& i(k)=i_{\mathrm{c} \beta}(k)-A_{\mathrm{i} 0}-\sum_{h} A_{\mathrm{i} h} \cos \left(h \omega_{\mathrm{g}} k T_{\mathrm{s}}+\phi_{\mathrm{i} h}\right)
\end{aligned}
$$

where the magnitudes $A_{\mathrm{u} h}$ and $A_{\mathrm{i} h}$ and the phase angles $\phi_{\mathrm{u} h}$ and $\phi_{\mathrm{i} h}$ can be efficiently computed using the Goertzel algorithm (cf. Appendix B). Here, the average and the harmonic components $h=\{1,5,7\}$ are chosen to be removed, but removing only the fundamental component $h=1$ would already give satisfactory results.

\section{Model Structure}

The selection of a model structure is essential for successful identification. The model structure used in the identification is derived in the following. Since the grid-frequency harmonic components are removed from the data, the plant model (4) reduces to

$$
i(k)=Y_{\mathrm{c}}(z) u(k)+i_{\mathrm{n}}(k)
$$

where noise $i_{\mathrm{n}}$ is taken into account. It is worth noticing that $u$ and $i$ are nonzero due to the wide-band PRBS voltage excitation. The model (10) is rewritten as

$$
i(k)=\frac{B(z)}{A(z)} u(k)+\frac{C(z)}{A(z)} w(k)
$$

where the denominator and numerator, respectively, of the pulse-transfer operator $Y_{\mathrm{c}}(z)$ are

$$
\begin{aligned}
& A(z)=1+a_{1} z^{-1}-a_{1} z^{-2}-z^{-3} \\
& B(z)=z^{-1}\left(b_{1} z^{-1}+b_{2} z^{-2}+b_{1} z^{-3}\right)
\end{aligned}
$$

The noise is modeled as $i_{\mathrm{n}}(k)=[C(z) / A(z)] w(k)$, where $C(z)$ is the noise polynomial and $w$ represents the white noise with zero mean. The second-order noise polynomial suffices

$$
C(z)=1+c_{1} z^{-1}+c_{2} z^{-2}
$$

Fig. 3 illustrates the model (11), which corresponds to the ARMAX model structure [32]. This structure has enough degrees of freedom to describe the properties of the disturbances affecting the converter current.

The model (11) has five independent parameters. It can be reformulated as a regression model,

$$
y(k)=\boldsymbol{\varphi}^{\mathrm{T}}(k) \boldsymbol{\theta}+w(k)
$$

where the regressed variable is

$$
y(k)=i(k)-i(k-3)
$$

and the regressors and the parameter vector, respectively, are

$$
\boldsymbol{\varphi}=\left[\begin{array}{c}
i(k-2)-i(k-1) \\
u(k-2)+u(k-4) \\
u(k-3) \\
w(k-1) \\
w(k-2)
\end{array}\right] \quad \boldsymbol{\theta}=\left[\begin{array}{l}
a_{1} \\
b_{1} \\
b_{2} \\
c_{1} \\
c_{2}
\end{array}\right]
$$

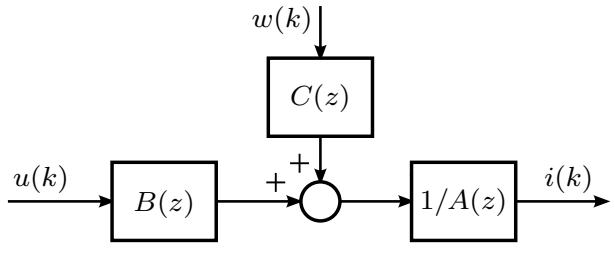

Fig. 3. ARMAX model structure.

\section{E. Parameter Estimates}

The desired parameter estimates $\hat{a}_{1}, \hat{b}_{1}$, and $\hat{b}_{2}$ for the parameters $a_{1}, b_{1}$, and $b_{2}$ are computed recursively based on (15). As a side product, the estimates $\hat{c}_{1}$ and $\hat{c}_{2}$ for the noise polynomial parameters are also obtained. The recursive method allows easier implementation in real-time processors.

Various recursive methods exist, such as a recursive least squares (RLS) method, a recursive pseudolinear regression (RPLR) method, and a recursive prediction error (RPE) method [37]. If the noise term is colored as with ARMAX model structures, the RLS method gives biased parameter estimates, while the RPE method has proven to be effective with the ARMAX model structure [37]. The RPE method requires initial estimate values that are close enough to the final values. The initial values can be obtained, e.g., by using the RLS or RPLR method. In this paper, the RPLR method is used for the initial value calculation and the final values are calculated using the RPE method (cf. Appendix C).

The continuous-time parameter estimates $\hat{\omega}_{\mathrm{p}}, \hat{L}_{\mathrm{fc}}$, and $\hat{L}_{\mathrm{fg}}$ can be solved from (3) and (6) using the parameter estimates $\hat{a}_{1}, \hat{b}_{1}$, and $\hat{b}_{2}$ as discussed in [36]:

$$
\begin{aligned}
& \hat{\omega}_{\mathrm{p}}=\frac{1}{T_{\mathrm{s}}} \arccos \left(-\frac{\hat{a}_{1}+1}{2}\right) \\
& \hat{L}_{\mathrm{fc}}=\frac{2 \frac{\sin \left(\hat{\omega}_{\mathrm{p}} T_{\mathrm{s}}\right)}{\hat{\omega}_{\mathrm{p}}}\left[\cos \left(\hat{\omega}_{\mathrm{p}} T_{\mathrm{s}}\right)-1\right]}{2 \hat{b}_{1}\left[\cos \left(\hat{\omega}_{\mathrm{p}} T_{\mathrm{s}}\right)-\frac{\sin \left(\hat{\omega}_{\mathrm{p}} T_{\mathrm{s}}\right)}{\hat{\omega}_{\mathrm{p}} T_{\mathrm{s}}}\right]+\hat{b}_{2}\left[1-\frac{\sin \left(\hat{\omega}_{\mathrm{p}} T_{\mathrm{s}}\right)}{\hat{\omega}_{\mathrm{p}} T_{\mathrm{s}}}\right]} \\
& \hat{L}_{\mathrm{fg}}=-\frac{\hat{\omega}_{\mathrm{p}} \hat{L}_{\mathrm{fc}}\left[\hat{L}_{\mathrm{fc}} \hat{b}_{2}+2 T_{\mathrm{s}} \cos \left(\hat{\omega}_{\mathrm{p}} T_{\mathrm{s}}\right)\right]}{\hat{\omega}_{\mathrm{p}} \hat{L}_{\mathrm{fc}} \hat{b}_{2}+2 \sin \left(\hat{\omega}_{\mathrm{p}} T_{\mathrm{s}}\right)} \\
& \hat{C}_{\mathrm{f}}=\frac{\hat{L}_{\mathrm{fc}}+\hat{L}_{\mathrm{fg}}}{\hat{\omega}_{\mathrm{p}}^{2} \hat{L}_{\mathrm{fc}} \hat{L}_{\mathrm{fg}}}
\end{aligned}
$$

\section{EXPERIMENTAL RESULTS}

The proposed method was evaluated by means of experiments. The experiments were carried out using the setup shown in Fig. 4(a). As illustrated in Fig. 4(b), the setup consists of two back-to-back connected 12.5-kVA $50-\mathrm{Hz}$ converters equipped with LCL filters. Additional grid-side inductors, marked with $L_{\mathrm{g}}$ in Fig. 4(b), can be connected between the LCL filter and the grid, in order to emulate weaker grid conditions. An isolation transformer was used for the load converter. Control and data acquisition of the converter under test were implemented on the dSPACE DS1006 board. The DC-bus voltage and the converter phase currents were measured. The nominal system parameters are given in Table I, where $u_{\mathrm{g}}$ is the nominal peak-value phase-to-neutral grid voltage, $\omega_{\mathrm{g}}$ is the nominal grid angular frequency, and $i_{\mathrm{N}}$ is the nominal peak-value converter current. 


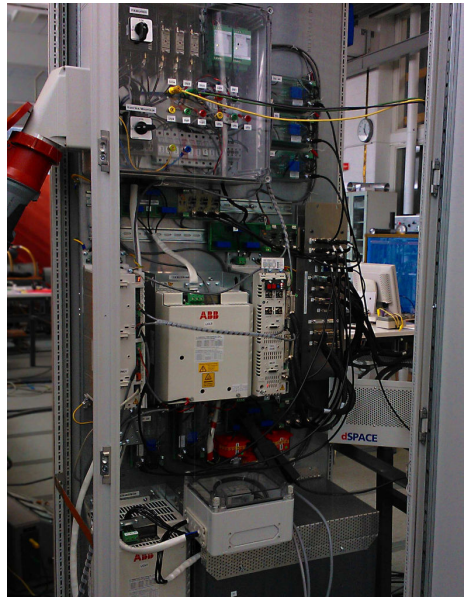

(a)

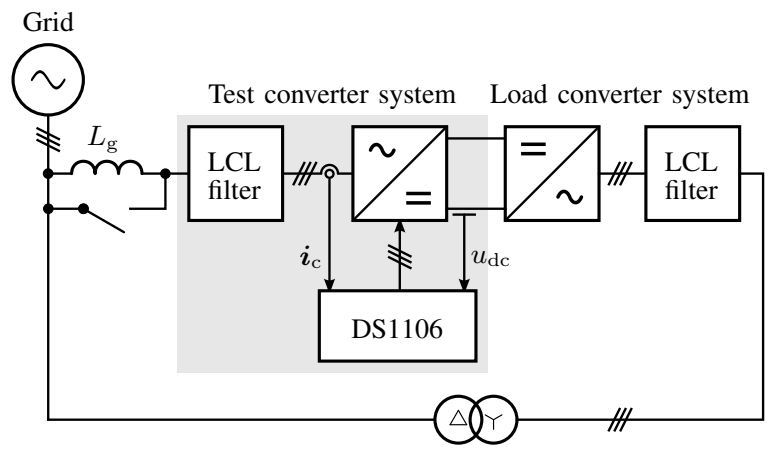

(b)

Fig. 4. Experimental setup: (a) photograph; (b) schematics.

TABLE I

NOMINAL PARAMETERS

\begin{tabular}{c|c|c|c}
\hline Parameter & Value & Parameter & Value \\
\hline$u_{\mathrm{g}}$ & $\sqrt{2 / 3} \cdot 400 \mathrm{~V}$ (1 p.u.) & $L_{\mathrm{fc}}$ & $3.3 \mathrm{mH}(0.081$ p.u. $)$ \\
$\omega_{\mathrm{g}}$ & $2 \pi \cdot 50 \mathrm{rad} / \mathrm{s}(1 \mathrm{p.u})$ & $C_{\mathrm{f}}$ & $8.8 \mu \mathrm{F}(0.035$ p.u. $)$ \\
$i_{\mathrm{N}}$ & $\sqrt{2} \cdot 18 \mathrm{~A}(1 \mathrm{p} . u)$. & $L_{\mathrm{fg}}$ & $3.0 \mathrm{mH}(0.073$ p.u. $)$ \\
\hline
\end{tabular}

\section{A. Identification}

During the identification, the converter was controlled using a state-feedback current controller [5] augmented with a gridvoltage sensorless observer [38] (cf. Appendix D), but any other PWM-based control scheme could be used instead. The switching frequency of the converter is $5 \mathrm{kHz}$ and the sampling frequency is $f_{\mathrm{s}}=10 \mathrm{kHz}$, i.e., the sampling period $T_{\mathrm{s}}=$ $100 \mu \mathrm{s}$. The converter was operating as a rectifier, under a constant load of 0.4 p.u.

The PRBS, having the amplitude of \pm 0.1 p.u., is injected into the $\beta$-component of the converter voltage reference, $\boldsymbol{v}=\mathrm{j} v_{\beta}$. The PRBS is generated at the sampling frequency $f_{\mathrm{s}}$ using a 9-bit-length shift register. Two PRBS periods are used, giving totally 1022 samples. The sequences $\left\{u_{\mathrm{c} \beta \text {,ref }}(k)\right\}$ and $\left\{i_{\mathrm{c} \beta}(k)\right\}$ stored for the identification consist of $N=1000$ samples, i.e., the duration $N T_{\mathrm{s}}=100 \mathrm{~ms}$ corresponds to five grid periods of $20 \mathrm{~ms}$. The fundamental component and the 5th and 7th harmonic components are removed from the sequences.
Three identification cases with different additional grid-side inductances $L_{\mathrm{g}}$ are presented in the following. In Case 1, no additional grid-side inductance was added. Fig. 5 shows the injected PRBS $v_{\beta}$, the real and imaginary components $u_{\mathrm{c} \alpha \text {, ref }}$ and $u_{\mathrm{c} \beta \text {,ref }}$, respectively, of the converter voltage reference, and the converter phase currents $i_{\mathrm{ca}}, i_{\mathrm{cb}}$, and $i_{\mathrm{cc}}$, when the PRBS is injected. ${ }^{1}$ Fig. 6 shows the preprocessed signals $u$ and $i$, after removing the fundamental and the 5 th and 7 th harmonic components.

Fig. 7 shows the recursively calculated parameter estimates, whose final values are: $\hat{L}_{\mathrm{fc}}=0.082$ p.u.; $\hat{C}_{\mathrm{f}}=0.031$ p.u.; $\hat{L}_{\mathrm{fg}}=0.080$ p.u. Their relative errors with respect to the nominal values are $2 \%$ for $\hat{L}_{\mathrm{fc}}, 12 \%$ for $\hat{C}_{\mathrm{f}}$, and $8 \%$ for $\hat{L}_{\mathrm{fg}}$. The grid-side inductance estimate $\hat{L}_{\mathrm{fg}}$ is slightly larger than the nominal grid-side inductance of the filter, which is expected due to the actual grid inductance. Unmodeled dynamics, nonlinearities, and inaccuracies in the transfer characteristics of the actuator and the measurement channel cause some errors in the estimated physical parameters. On the other hand, the identified model is well suited for the digital control purposes, since it inherently takes the intrinsic transfer characteristics of the converter system into account [39].

In Case 2, the parameter identification was repeated when an additional inductance $L_{\mathrm{g}}=0.025$ p.u. was used between the LCL filter and the grid. The effective grid-side inductance is then $L_{\mathrm{fg}}=0.098$ p.u. The identified values are: $\hat{L}_{\mathrm{fc}}=0.081$ p.u.; $\hat{C}_{\mathrm{f}}=0.031$ p.u.; $\hat{L}_{\mathrm{fg}}=0.105$ p.u. Hence, the proposed method detects the change of the grid-side inductance with very good accuracy.

In Case 3, the parameter identification was repeated when an additional inductance $L_{\mathrm{g}}=0.105$ p.u. was used between the LCL filter and the grid. The identified values are: $\hat{L}_{\mathrm{fc}}=0.081$ p.u.; $\hat{C}_{\mathrm{f}}=0.031$ p.u.; $\hat{L}_{\mathrm{fg}}=0.174$ p.u. Again, the proposed method detects the change of the grid-side inductance very well.

\section{B. Validation in the Frequency Domain}

The identified parameters of Case 1 are validated in the frequency domain. The converter-side input admittance of the filter was measured with the frequency-response analyzer NF FRA5097 when the grid-side terminals of the filter were shortcircuited. The measured response is compared with the calculated frequency response (2) using the identified parameters. Fig. 8 shows the measured and calculated responses. As can be seen, the calculated frequency response matches well with the measured response; the identified model predicts very well the resonance and anti-resonance frequencies as well as the slopes at high and low frequencies.

\section{Example of Using the Identified Parameters}

The controller [5], [38] was tuned using the estimated parameters of the LCL filter. The current-reference tracking bandwidth was set to $600 \mathrm{~Hz}$. Fig. 9 shows the measured

\footnotetext{
${ }^{1}$ During the PRBS excitation, the harmonic contents in the grid currents were: 0.03 p.u. (a-phase); 0.08 p.u. (b-phase); and 0.07 p.u. (c-phase). The harmonics were computed up to the 50th order.
} 

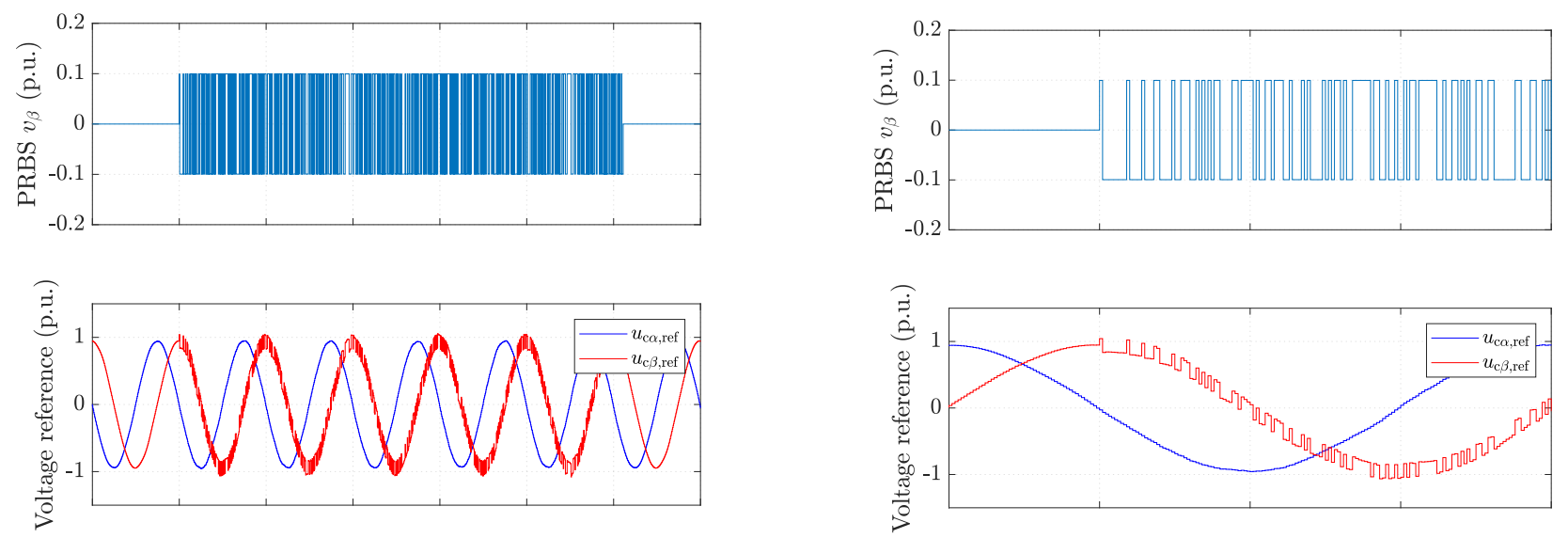

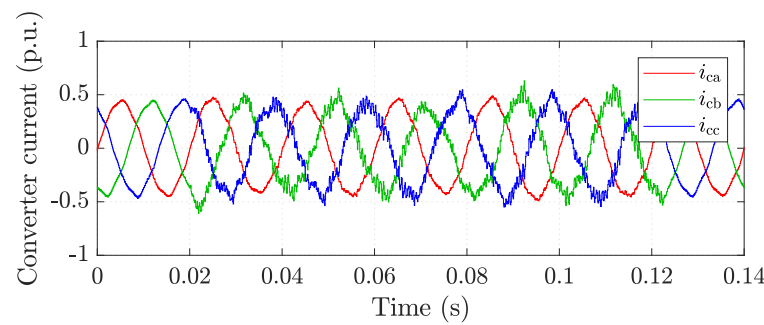

(a)

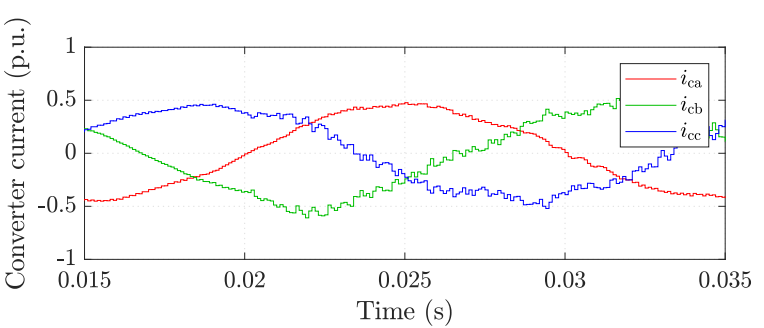

(b)

Fig. 5. Measured waveforms during identification: (a) total duration of the experiment; (b) zoomed in over one grid period. The first subplot shows the injected PRBS, second subplot shows the converter voltage references, and the last subplot shows the converter phase currents. The system is excited between $0.02 \ldots 0.1222 \mathrm{~s}$.
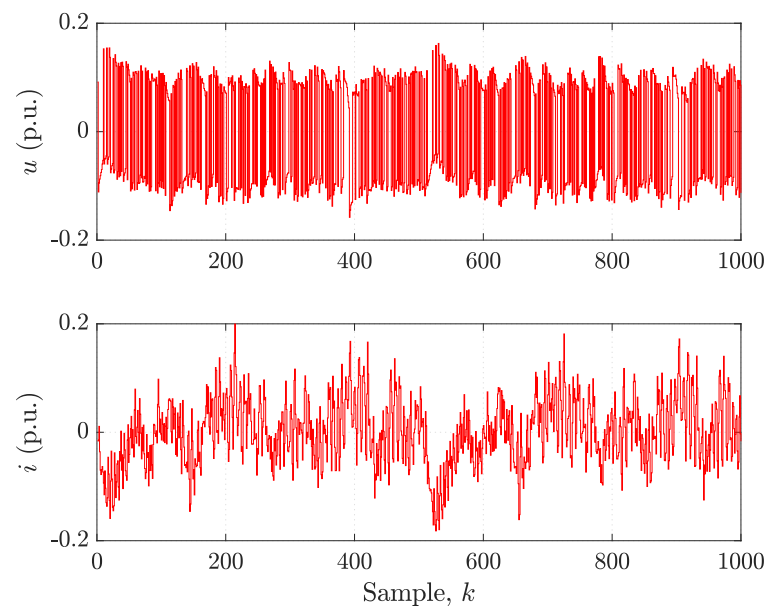

(a)
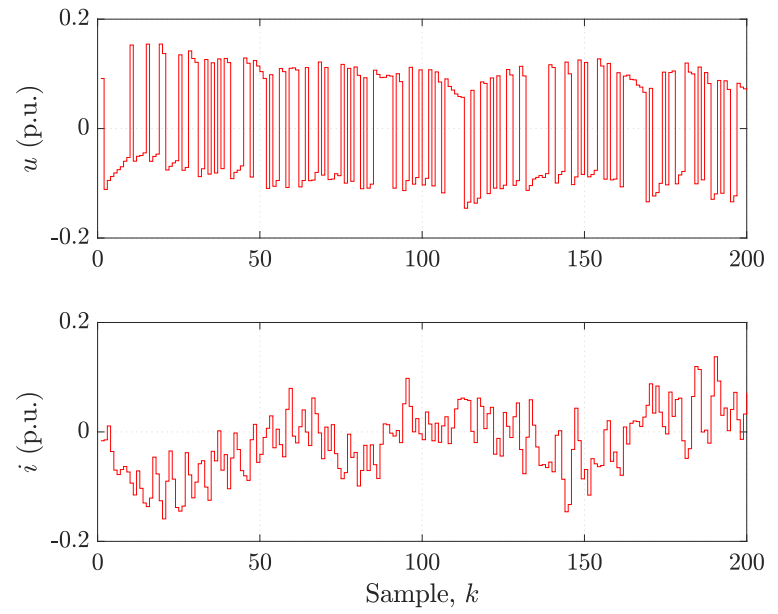

(b)

Fig. 6. Sequencies used for the identification after removing their fundamental, 5 th, and 7 th harmonic components: (a) total duration $N T_{\mathrm{s}}=100 \mathrm{~ms}$; (b) zoomed in over one grid period. The first subplot shows the preprocessed voltage reference $u$ and the second subplot shows the preprocessed converter current $i$.

waveforms of the converter current components in grid-voltage coordinates, when the reference for the q-axis current $i_{\mathrm{cq}}$ steps from zero to 0.4 p.u. at $t=0.01 \mathrm{~s}$. During the step, the reference for the d-axis current $i_{\mathrm{cd}}$ was kept at zero. As the figure shows, the step response with the identified parameters matches well with the designed dynamics: 5-\% settling time is $1 \mathrm{~ms}$ and there is no overshoot. This test indicates that the identified parameters can be used to tune the controller, enabling the self-commissioning of the converter. As a baseline, Fig. 9 also shows the step response for the controller, which is tuned based on the nominal parameters.

\section{DISCUSSION}

\section{A. Simulation-Based Sensitivity Analyses}

Only experimental results were shown in the previous section. Here, we elaborate on some accuracy and sensitivity aspects of the proposed method by means of simulations of the $12.5-\mathrm{kVA} 50-\mathrm{Hz}$ converter system (cf. Table I). Unlike in the experiments, the actual parameter values of the plant 

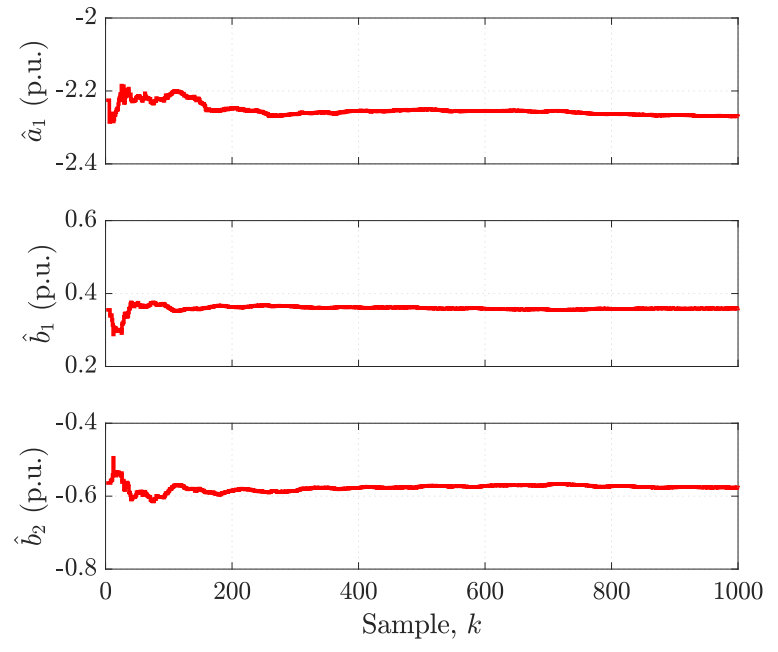

(a)
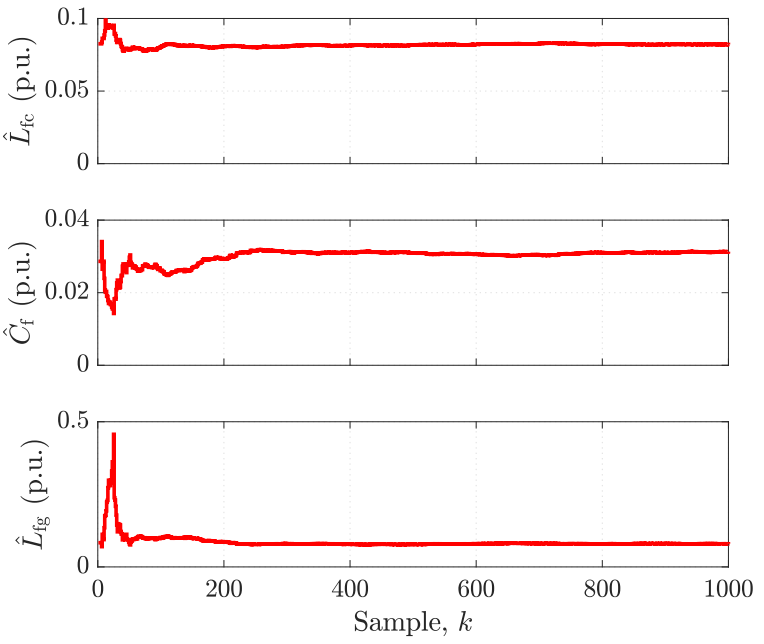

(b)

Fig. 7. Recursively identified parameters: (a) discrete-time model parameters; (b) corresponding continuous-time model parameters.
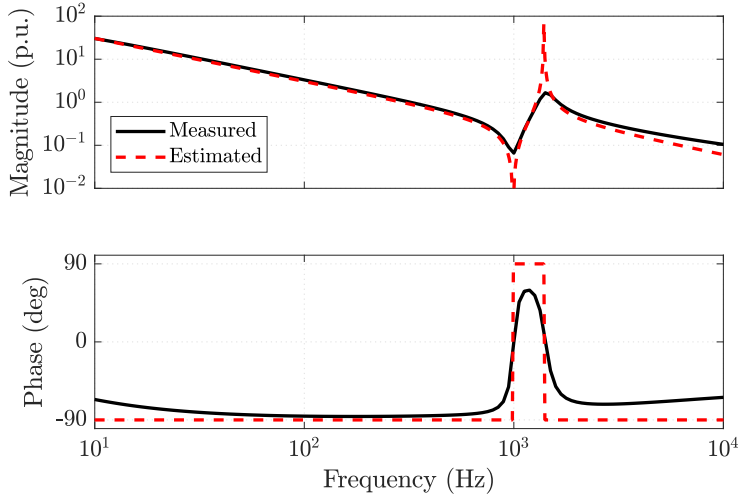

Fig. 8. Measured LCL-filter input admittance $\boldsymbol{i}_{\mathrm{c}}(\mathrm{j} \omega) / \boldsymbol{u}_{\mathrm{c}}(\mathrm{j} \omega)$ (solid black line) and the input admittance calculated using the identified parameters (dashed red line).
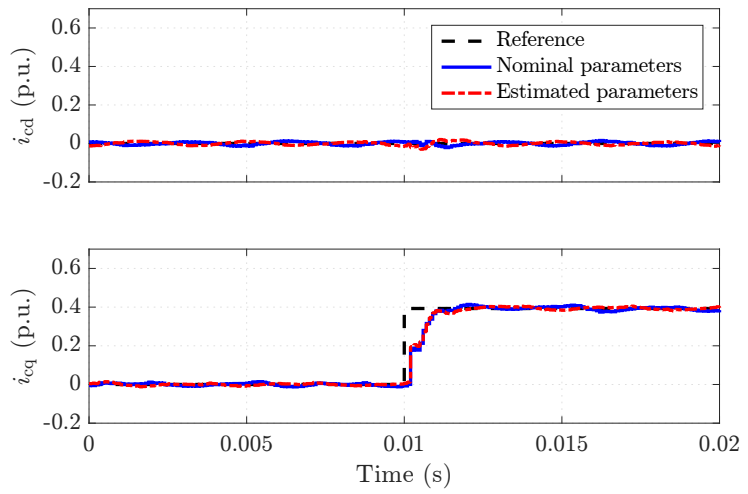

Fig. 9. Measured waveforms of the $d$ - and q-current components when the state-feedback controller is tuned using the nominal parameters (solid blue line) and the estimated parameters (dash-dotted red line).

are exactly known in the simulations, which enables better analysis of estimation errors.

In the following tests, the parameters are identified under a constant load of 0.4 p.u. when the converter operates as a rectifier. The measurement noise with a standard deviation of 0.02 p.u. is added to the phase current measurements. The PWM of the converter is included in the simulation model. As in the experiments, the converter is controlled using a statefeedback current controller [5] augmented with a grid-voltage sensorless observer [38]. The identification method was also tested with a PI-type current controller [4], which resulted in almost identical parameter estimates under the same closedloop control bandwidth conditions.

1) Closed-Loop Bandwidth: The noise $i_{\mathrm{n}}$ in (10) and the excitation signal are correlated due to the feedback loop in the identification method. Generally, it is necessary to use a proper noise model in closed-loop identification in order to get consistent estimates [32], [39]. Different closed-loop bandwidths for the converter current control were tested using simulations. When the current-control bandwidth is $100 \mathrm{~Hz}$, the errors in the estimated parameters are negligible, despite the noise in the measured converter currents. This example indicates that the selected noise model in (11) is sufficient.

When the current-control bandwidth is set to $600 \mathrm{~Hz}$, the relative error in the capacitance estimate $\hat{C}_{\mathrm{f}}$ is about $10 \%$, while the errors in the other two estimates are smaller. The accuracy of the parameter estimates decreases as the closed-loop bandwidth increases, which is an expected trend in closedloop identification [32]. For this reason, a low current-control bandwidth should preferably be used during the identification process. In the following, the current-controller bandwidth of $100 \mathrm{~Hz}$ is used.

2) Grid Impedance: The proposed method was tested with different grid impedances. In the first example, the grid impedance is modelled with the series inductance of 0.2 p.u. The inductance estimate $\hat{L}_{\mathrm{fg}}$ is the most biased parameter estimate with a relative error of $4 \%$, and the errors in the other two parameter estimates are less than $2 \%$. In the second example, the grid impedance is modelled with the series inductance of 0.2 p.u. and the series resistance of 0.1 p.u. In this case also, the inductance estimate $\hat{L}_{\mathrm{fg}}$ is the most biased parameter estimate with a relative error of $4 \%$, and the errors in the other two parameter estimates are less than $2 \%$. In the third 
TABLE II

Number of Operations Per Recursion Step

\begin{tabular}{c|c|c|c|c}
\hline Operation & Goertzel & RPLR & RPE & Total \\
\hline Addition & 12 & 95 & 103 & 210 \\
Multiplication & 6 & 135 & 141 & 309 \\
Division & 0 & 1 & 1 & 2 \\
\hline
\end{tabular}

example, the grid impedance was modelled with the series inductance of 0.5 p.u. to represent a very weak grid. In this case, the inductance estimate $\hat{L}_{\mathrm{fg}}$ is the most biased parameter estimate with a relative error of $12 \%$. The errors in the other two parameter estimates are less than $3 \%$.

3) Grid Frequency: The grid frequency may deviate around its nominal value. In the case of $50-\mathrm{Hz}$ grids, a typical range of allowed variation is $49.9 \ldots 50.1 \mathrm{~Hz}$. The proposed method needs the grid-frequency value for removing the fundamental and the undesired harmonic components from the stored sequences. In order to study the sensitivity of the parameter estimates to the grid frequency, the actual grid frequency in the plant model was set to $49.8 \mathrm{~Hz}$, while the identification method used the value of $50 \mathrm{~Hz}$. The most biased parameter estimate is $\hat{L}_{\mathrm{fg}}$, with a relative error of $6 \%$. However, since converter control algorithms typically estimate the instantaneous value of the grid frequency (either via a phase-locked loop or via a gridvoltage sensorless methods, e.g., [38]), an up-to-date value of the grid frequency could be easily used in the proposed identification method.

\section{B. Implementation Aspects in Real-Time Processors}

Applicability of the proposed method in real-time processors depends on various factors, including the processor architecture, clock frequency, and memory. Table II shows the number of basic operations per recursion step (or per sample) for the proposed method. In order to get a rough idea of the required total computation time, let us make the following assumptions: the number of samples is $N=$ 1000 ; the processor clock frequency is $100 \mathrm{MHz}$; $1 \%$ of the processing power is used for computing the parameters; addition and multiplication take two clock cycles to complete; the division takes 15 clock cycles to complete; and data transfer latencies between the processor and the memory are omitted. These assumptions lead to the total computation time of approximately one second. In practice, the data transfer latencies increase the total computation time, which, however, remains in the acceptable range. Furthermore, 2000 32-bit memory locations are required for storing the sequences in (8), and some additional memory is needed for the recursive algorithms. Based on this simplistic analysis, the proposed method could be run in a real-time processor as a background process, employing the data stored into the memory.

\section{CONCLUSIONS}

We have proposed a method to identify both the discretetime parameters and the physical parameters of an LCL filter model. Only the converter phase currents and the DC-bus voltage need to be measured. The proposed method can be added to any existing PWM-based converter control system in a plug-in manner. To improve the accuracy of the parameter estimates, the closed-loop control bandwidth should preferably be low during the short identification process. The proposed method can provide the filter parameter estimates for the converter control during the start-up. Furthermore, the method can be run occasionally during the normal operation of the converter, in order to obtain an estimate for the total grid-side inductance. The parameter estimates can be beneficial also for condition monitoring and fault diagnosis purposes. According to the simulation and experimental results, the filter parameters can be estimated with a very good accuracy and changes in the grid-side inductance can be detected.

\section{APPENDIX A DISCRETE-TIME MODEL}

A discrete-time model of the lossless LCL filter in stationary coordinates is presented in the following. The PWM is modeled as the zero-order hold $(\mathrm{ZOH})$. The sampling of the converter currents and the grid voltages are synchronized with the PWM. Under these assumptions, the hold-equivalent discrete-time state-space model of the LCL filter becomes [5]

$$
\begin{aligned}
\mathbf{x}(k+1) & =\mathbf{A x}(k)+\mathbf{B}_{\mathrm{c}} \boldsymbol{u}_{\mathrm{c}}(k)+\mathbf{B}_{\mathrm{g}} \boldsymbol{u}_{\mathrm{g}}(k) \\
\boldsymbol{i}_{\mathrm{c}}(k) & =\mathbf{C x}(k)
\end{aligned}
$$

where the state vector is selected as $\mathbf{x}=\left[\boldsymbol{i}_{\mathrm{c}}, \boldsymbol{u}_{\mathrm{f}}, \boldsymbol{i}_{\mathrm{g}}\right]^{\mathrm{T}}$. The system matrices are

$$
\begin{gathered}
\mathbf{A}=\left[\begin{array}{ccc}
\frac{L_{\mathrm{fc}}+L_{\mathrm{fg}} \cos \left(\omega_{\mathrm{p}} T_{\mathrm{s}}\right)}{L_{\mathrm{fc}}+L_{\mathrm{fg}}} & -\frac{\sin \left(\omega_{\mathrm{p}} T_{\mathrm{s}}\right)}{\omega_{\mathrm{p}} L_{\mathrm{fc}}} & \frac{L_{\mathrm{fg}}\left[1-\cos \left(\omega_{\mathrm{p}} T_{\mathrm{s}}\right)\right]}{L_{\mathrm{fc}}+L_{\mathrm{fg}}} \\
\frac{\sin \left(\omega_{\mathrm{p}} T_{\mathrm{s}}\right)}{\omega_{\mathrm{p}} C_{\mathrm{f}}} & \cos \left(\omega_{\mathrm{p}} T_{\mathrm{s}}\right) & -\frac{\sin \left(\omega_{\mathrm{p}} T_{\mathrm{s}}\right)}{\omega_{\mathrm{p}} C_{\mathrm{f}}} \\
\frac{L_{\mathrm{fc}}\left[1-\cos \left(\omega_{\mathrm{p}} T_{\mathrm{s}}\right)\right]}{L_{\mathrm{fc}}+L_{\mathrm{fg}}} & \frac{\sin \left(\omega_{\mathrm{p}} T_{\mathrm{s}}\right)}{\omega_{\mathrm{p}} L_{\mathrm{fg}}} & \frac{L_{\mathrm{fg}}+L_{\mathrm{fc}} \cos \left(\omega_{\mathrm{p}} T_{\mathrm{s}}\right)}{L_{\mathrm{fc}}+L_{\mathrm{fg}}}
\end{array}\right] \\
\mathbf{B}_{\mathrm{c}}=\frac{1}{L_{\mathrm{fc}}+L_{\mathrm{fg}}}\left[\begin{array}{c}
T_{\mathrm{s}}+\frac{L_{\mathrm{fg}} \sin \left(\omega_{\mathrm{p}} T_{\mathrm{s}}\right)}{\omega_{\mathrm{p}} L_{\mathrm{fc}}} \\
L_{\mathrm{fg}}\left[1-\cos \left(\omega_{\mathrm{p}} T_{\mathrm{s}}\right)\right] \\
T_{\mathrm{s}}-\frac{\sin \left(\omega_{\mathrm{p}} T_{\mathrm{s}}\right)}{\omega_{\mathrm{p}}}
\end{array}\right] \quad \mathbf{C}=\left[\begin{array}{lll}
1 & 0 & 0
\end{array}\right]
\end{gathered}
$$

The closed-form expression for the input matrix $\mathbf{B}_{\mathrm{g}}$ can be found in [5]. The converter current $\boldsymbol{i}_{\mathrm{c}}(k)$ can be solved as

$$
\begin{aligned}
\boldsymbol{i}_{\mathrm{c}}(k) & =\mathbf{C}(z \mathbf{I}-\mathbf{A})^{-1} \mathbf{B}_{\mathrm{c}} \boldsymbol{u}_{\mathrm{c}}(k) \\
& =\frac{b_{1} z^{-1}+b_{2} z^{-2}+b_{1} z^{-3}}{1+a_{1} z^{-1}-a_{1} z^{-2}-z^{-3}} \boldsymbol{u}_{\mathrm{c}}(k)
\end{aligned}
$$

where the parameters $a_{1}, b_{1}$, and $b_{2}$ are given in (6). The actual converter voltage $\boldsymbol{u}_{\mathrm{c}}$ is produced based on the voltage reference $\boldsymbol{u}_{\mathrm{c}, \text { ref }}$. Due to the finite computational time of the control algorithm, the converter-voltage reference calculated at the present time step becomes active at the next time step

$$
\boldsymbol{u}_{\mathrm{c}}(k)=z^{-1} \boldsymbol{u}_{\mathrm{c}, \mathrm{ref}}(k)
$$

Combining (21) and (22) gives the pulse-transfer operator (5).

\section{APPENDIX B \\ DFT AND GOERTZEL ALGORITHM}

Consider a time-domain sequence of $N$ equally-spaced samples, $\{\boldsymbol{x}(k)\}=\{\boldsymbol{x}(0), \boldsymbol{x}(1), \ldots \boldsymbol{x}(N-1)\}$, which could be complex-valued in general. The spectral components can 
be computed using the discrete Fourier transformation (DFT) as

$$
\boldsymbol{c}_{n}=\frac{1}{N} \sum_{k=0}^{N-1} \boldsymbol{x}(k) \mathrm{e}^{-\mathrm{j} \omega_{n} k T_{\mathrm{s}}}
$$

where $\omega_{n}=2 \pi n /\left(N T_{\mathrm{s}}\right)$ is the $n$th angular frequency component. The inverse transformation is

$$
\boldsymbol{x}(k)=\sum_{n=0}^{N-1} \boldsymbol{c}_{n} \mathrm{e}^{\mathrm{j} \omega_{n} k T_{\mathrm{s}}}
$$

For real-valued sequences $\{x(k)\}$, such as those in (8), $\boldsymbol{c}_{N-n}=\boldsymbol{c}_{n}^{*}$ holds, giving an alternative form [40]

$$
x(k)=A_{0}+\sum_{n=1}^{N / 2} A_{n} \cos \left(\omega_{n} k T_{\mathrm{s}}+\phi_{n}\right)
$$

where $A_{0}=\left|\boldsymbol{c}_{0}\right|, A_{n}=2\left|\boldsymbol{c}_{n}\right|, \phi_{n}=\arg \left(\boldsymbol{c}_{n}\right)$, and the last index in the summation assumes $N$ to be even.

The fast Fourier transformation (FFT) could be used to compute the full spectrum in (23). However, just a few selected grid-frequency harmonic components (e.g. $\omega_{n}=h \omega_{\mathrm{g}}$, where $h=\{1,5,7\}$ ) need to be computed in the preprocessing stage. The Goertzel algorithm can be used to efficiently compute individual spectral components $c_{n}$, instead of computing the FFT [40]. The Goertzel algorithm is recursive and it can be easily implemented with real-valued arithmetics.

\section{APPENDIX C \\ PARAmeter Computation Algorithm}

An estimate $\hat{\boldsymbol{\theta}}=\left[\hat{a}_{1}, \hat{b}_{1}, \hat{b}_{2}, \hat{c}_{1}, \hat{c}_{2}\right]^{\mathrm{T}}$ for the parameter vector $\boldsymbol{\theta}$ is estimated recursively using the prediction error

$$
\hat{w}(k)=y(k)-\hat{\boldsymbol{\varphi}}(k)^{\mathrm{T}} \hat{\boldsymbol{\theta}}(k-1)
$$

where $\hat{\varphi}$ is the regressor vector similar to $\varphi$ but the noise terms $w$ are replaced with the estimated terms $\hat{w}$ :

$$
\hat{\varphi}(k)=\left[\begin{array}{c}
i(k-2)-i(k-1) \\
u(k-2)+u(k-4) \\
u(k-3) \\
\hat{w}(k-1) \\
\hat{w}(k-2)
\end{array}\right]
$$

In the RPLR method [37], the parameter vector is estimated

$$
\hat{\boldsymbol{\theta}}(k)=\hat{\boldsymbol{\theta}}(k-1)+\mathbf{K}(k) \hat{w}(k)
$$

The gain $\mathbf{K}(k)$ is calculated as

$$
\mathbf{K}(k)=\mathbf{P}(k) \hat{\boldsymbol{\varphi}}(k)=\frac{\mathbf{P}(k-1) \hat{\boldsymbol{\varphi}}(k)}{\lambda+\hat{\boldsymbol{\varphi}}^{\mathrm{T}}(k) \mathbf{P}(k-1) \hat{\boldsymbol{\varphi}}(k)}
$$

where $\lambda$ is a forgetting factor and

$$
\mathbf{P}(k)=\frac{\mathbf{P}(k-1)}{\lambda}-\frac{\mathbf{P}(k-1) \hat{\boldsymbol{\varphi}}(k) \hat{\boldsymbol{\varphi}}(k)^{\mathrm{T}} \mathbf{P}(k-1)}{\lambda\left[\lambda+\hat{\boldsymbol{\varphi}}^{\mathrm{T}}(k) \mathbf{P}(k-1) \hat{\boldsymbol{\varphi}}(k)\right]}
$$

Alternatively, the parameter vector can be estimated using the RPE method [37], where $\mathbf{K}$ and $\mathbf{P}$ are replaced with

$$
\mathbf{K}(k)=\mathbf{P}(k) \boldsymbol{\psi}(k)=\frac{\mathbf{P}(k-1) \boldsymbol{\psi}(k)}{\lambda+\boldsymbol{\psi}^{\mathrm{T}}(k) \mathbf{P}(k-1) \boldsymbol{\psi}(k)}
$$

and

$$
\mathbf{P}(k)=\frac{\mathbf{P}(k-1)}{\lambda}-\frac{\mathbf{P}(k-1) \boldsymbol{\psi}(k) \boldsymbol{\psi}(k)^{\mathrm{T}} \mathbf{P}(k-1)}{\lambda\left[\lambda+\boldsymbol{\psi}^{\mathrm{T}}(k) \mathbf{P}(k-1) \boldsymbol{\psi}(k)\right]}
$$

An approximate gradient is computed by filtering $u, i$, and $\hat{w}$,

$$
\begin{aligned}
& \psi(k)=\left[\begin{array}{c}
i_{\mathrm{F}}(k-2)-i_{\mathrm{F}}(k-1) \\
u_{\mathrm{F}}(k-2)+u_{\mathrm{F}}(k-4) \\
u_{\mathrm{F}}(k-3) \\
\hat{w}_{\mathrm{F}}(k-1) \\
\hat{w}_{\mathrm{F}}(k-2)
\end{array}\right] \\
& i_{\mathrm{F}}(k)=i(k)-\hat{c}_{1}(k) i_{\mathrm{F}}(k-1)-\hat{c}_{2}(k) i_{\mathrm{F}}(k-2) \\
& u_{\mathrm{F}}(k)=u(k)-\hat{c}_{1}(k) u_{\mathrm{F}}(k-1)-\hat{c}_{2}(k) u_{\mathrm{F}}(k-2) \\
& \hat{w}_{\mathrm{F}}(k)=\hat{w}(k)-\hat{c}_{1}(k) \hat{w}_{\mathrm{F}}(k-1)-\hat{c}_{2}(k) \hat{w}_{\mathrm{F}}(k-2)
\end{aligned}
$$

Initial values for $\hat{\boldsymbol{\theta}}$ and $\mathbf{P}$ are needed in order to start the recursive calculation. Here, the initial values are $\hat{\boldsymbol{\theta}}_{\mathrm{RPLR}}(0)=$ 0 and $\mathbf{P}_{\text {RPLR }}(0)=1000 \mathbf{I}$ p.u. for the RPLR method. The initial values for the RPE method are $\hat{\boldsymbol{\theta}}_{\mathrm{RPE}}(0)=\hat{\boldsymbol{\theta}}_{\mathrm{RPLR}}(N-$ $1)$, where $\hat{\boldsymbol{\theta}}_{\mathrm{RPLR}}$ is the parameter estimate given by the RPLR, and $\mathbf{P}_{\mathrm{RPE}}(0)=1000 \mathbf{I}$ p.u. The forgetting factor is $\lambda=1$.

\section{APPENDIX D \\ DEsign PARAMETERS OF THE CONTROLLER}

The design parameters used in the current control method [5] are $\omega_{\mathrm{cd}}=2 \pi \cdot 100 \mathrm{rad} / \mathrm{s}, \zeta_{\mathrm{cd}}=1, \omega_{\mathrm{cr}}=2 \pi \cdot 1350$ $\mathrm{rad} / \mathrm{s}$, and $\zeta_{\mathrm{cr}}=0.01$. The design parameters used in the gridvoltage sensorless observer [38] are $\alpha_{\mathrm{od}}=5 \omega_{\mathrm{cd}}, \omega_{\mathrm{or}}=\omega_{\mathrm{cr}}$, $\zeta_{\text {or }}=0.7, \alpha_{\mathrm{u}}=2 \pi \cdot 50 \mathrm{rad} / \mathrm{s}, \omega_{\omega}=2 \pi \cdot 25 \mathrm{rad} / \mathrm{s}$, and $\zeta_{\omega}=1$. The notation corresponds to that used in [5], [38], where the control architecture and tuning process is thoroughly described. The DC-bus voltage controller is a PI controller, having the bandwidth of $5 \mathrm{~Hz}$.

\section{REFERENCES}

[1] K. Jalili and S. Bernet, "Design of LCL filters of active-front-end twolevel voltage-source converters," IEEE Trans. Ind. Electron., vol. 56, no. 5, pp. 1674-1689, May 2009.

[2] Y. Jiao and F. Lee, "LCL filter design and inductor current ripple analysis for a three-level NPC grid interface converter," IEEE Trans. Power Electron., vol. 30, no. 9, pp. 4659-4668, Sept. 2015.

[3] S. Jayalath and M. Hanif, "Generalized LCL-filter design algorithm for grid-connected voltage-source inverter," IEEE Trans. Ind. Electron., vol. 64, no. 3, pp. 1905-1915, Mar. 2017.

[4] L. Harnefors, L. Zhang, and M. Bongiorno, "Frequency-domain passivity-based current controller design," IET Power Electronics, vol. 1, no. 4, pp. 455-465, 2008.

[5] J. Kukkola, M. Hinkkanen, and K. Zenger, "Observer-based state-space current controller for a grid converter equipped with an LCL filter: Analytical method for direct discrete-time design," IEEE Trans. Ind. Appl., vol. 51, no. 5, pp. 4079-4090, Sept./Oct. 2015.

[6] C. A. Busada, S. G. Jorge, and J. A. Solsona, "Full-state feedback equivalent controller for active damping in LCL-filtered grid-connected inverters using a reduced number of sensors," IEEE Trans. Ind. Electron. vol. 62, no. 10, pp. 5993-6002, Oct. 2015.

[7] X. Zhang, Y. Wang, C. Yu, L. Guo, and R. Cao, "Hysteresis model predictive control for high-power grid-connected inverters with output LCL filter," IEEE Trans. Ind. Electron., vol. 63, no. 1, pp. 246-256, Jan. 2016.

[8] D. Pérez-Estévez, J. Doval-Gandoy, A. G. Yepes, and Ó. López, "Positive- and negative-sequence current controller with direct discretetime pole placement for grid-tied converters with LCL filter," IEEE Trans. Power Electron., vol. 32, no. 9, pp. 7207-7221, Sept. 2017. 
[9] B. Wang, Y. Xu, Z. Shen, Z. Jibin, C. Li, and H. Liu, "Current control of grid-connected inverter with LCL filter based on extendedstate observer estimations using single sensor and achieving improved robust observation dynamics," IEEE Trans. Ind. Electron., vol. 64, no. 7, pp. 5428-5439, July 2017.

[10] J. Rhode, A. Kelley, and M. Baran, "Complete characterization of utilization-voltage power system impedance using wideband measurement," IEEE Trans. Ind. Appl., vol. 33, no. 6, pp. 1472-1479, Nov. 1997.

[11] D. Reigosa, F. Briz, C. Charro, P. Garcia, and J. Guerrero, "Active islanding detection using high-frequency signal injection," IEEE Trans. Ind. Appl., vol. 48, no. 5, pp. 1588-1597, Sept. 2012.

[12] L. Asiminoaei, R. Teodorescu, F. Blaabjerg, and U. Borup, "Implementation and test of an online embedded grid impedance estimation technique for PV inverters," IEEE Trans. Ind. Electron., vol. 52, no. 4, pp. 11361144, Aug. 2005.

[13] M. Céspedes and J. Sun, "Online grid impedance identification for adaptive control of grid-connected inverters," in Proc. IEEE ECCE, Raleigh, NC, USA, Sept. 2012, pp. 914-921.

[14] S. Neshvad, S. Chatzinotas, and J. Sachau, "Wideband identification of power network parameters using pseudo-random binary sequences on power inverters," IEEE Trans. Smart Grid, vol. 6, no. 5, pp. 2293-2301, Sept. 2015.

[15] M. Sumner, A. Abusorrah, D. Thomas, and P. Zanchetta, "Real time parameter estimation for power quality control and intelligent protection of grid-connected power electronic converters," IEEE Trans. Smart Grid, vol. 5, no. 4, pp. 1602-1607, July 2014.

[16] D. Martin and E. Santi, "Autotuning of digital deadbeat current controllers for grid-tie inverters using wide bandwidth impedance identification," IEEE Trans. Ind. Appl., vol. 50, no. 1, pp. 441-451, Jan. 2014.

[17] T. Roinila, M. Vilkko, and J. Sun, "Online grid impedance measurement using discrete-interval binary sequence injection," IEEE Trans. Emerg. Sel. Topics Power Electron., vol. 2, no. 4, pp. 985-993, Dec. 2014.

[18] J. G. Norniella, J. M. Cano, G. A. Orcajo, C. H. R. Garcia, J. F. Pedrayes, M. F. Cabanas, and M. G. Melero, "Analytic and iterative algorithms for online estimation of coupling inductance in direct power control of three-phase active rectifiers," IEEE Trans. Power Electron., vol. 26, no. 11, pp. 3298-3307, Nov. 2011.

[19] V. Valdivia, A. Lazaro, A. Barrado, P. Zumel, C. Fernandez, and M. Sanz, "Black-box modeling of three-phase voltage source inverters for system-level analysis," IEEE Trans. Ind. Electron., vol. 59, no. 9, pp. 3648-3662, Sept. 2012.

[20] A. Vidal, A. G. Yepes, F. D. Freijedo, Ó. López, J. Malvar, F. Baneira, and J. Doval-Gandoy, "A method for identification of the equivalent inductance and resistance in the plant model of current-controlled gridtied converters," IEEE Trans. Power Electron., vol. 30, no. 12, pp. 7245 7261, Dec. 2015.

[21] B. Arif, L. Tarisciotti, P. Zanchetta, J. C. Clare, and M. Degano, "Grid parameter estimation using model predictive direct power control," IEEE Trans. Ind. Appl., vol. 51, no. 6, pp. 4614-4622, Nov. 2015.

[22] M. Liserre, F. Blaabjerg, and R. Teodorescu, "Grid impedance estimation via excitation of LCL-filter resonance," IEEE Trans. Ind. Appl., vol. 43, no. 5, pp. 1401-1407, Sept. 2007.

[23] S. Cobreces, E. Bueno, D. Pizarro, F. Rodriguez, and F. Huerta "Grid impedance monitoring system for distributed power generation electronic interfaces," IEEE Trans. Instrum. Meas., vol. 58, no. 9, pp. 3112-3121, Sept. 2009

[24] N. Hoffmann and F. Fuchs, "Minimal invasive equivalent grid impedance estimation in inductive-resistive power networks using extended Kalman filter," IEEE Trans. Power Electron., vol. 29, no. 2, pp. 631-641, Feb. 2014.

[25] P. Garcia, J. Guerrero, J. Garcia, A. Navarro-Rodriguez, and M. Sumner, "Low frequency signal injection for grid impedance estimation in three phase systems," in Proc. IEEE ECCE, Pittsburgh, PA, Sept. 2014, pp. 1542-1549.

[26] M. A. Azzouz and E. F. El-Saadany, "Multivariable grid admittance identification for impedance stabilization of active distribution networks," IEEE Trans. Smart Grid, vol. 8, no. 3, pp. 1116-1128, May 2017.

[27] A. Ghanem, M. Rashed, M. Sumner, M. A. Elsayes, and I. I. I. Mansy, "Grid impedance estimation for islanding detection and adaptive control of converters," IET Power Electronics, vol. 10, no. 11, pp. 1279-1288, 2017.

[28] J. Massing, M. Stefanello, H. Grundling, and H. Pinheiro, "Adaptive current control for grid-connected converters with LCL filter," IEEE Trans. Ind. Electron., vol. 59, no. 12, pp. 4681-4693, Dec. 2012.
[29] R. Peña Alzola, M. Liserre, F. Blaabjerg, M. Ordonez, and T. Kerekes, "A self-commissioning notch filter for active damping in a threephase LCL-filter-based grid-tie converter," IEEE Trans. Power Electron., vol. 29, no. 12, pp. 6754-6761, Dec. 2014.

[30] S. Gomez Jorge, C. Busada, and J. Solsona, "Frequency-adaptive current controller for three-phase grid-connected converters," IEEE Trans. Ind. Electron., vol. 60, no. 10, pp. 4169-4177, Oct. 2013.

[31] K. Godfrey, Ed., Perturbation signals for system identification. UK: Prentice Hall International, 1993.

[32] L. Ljung, System Identification: Theory for the User, 2nd ed. Troy, NY: Prentice-Hall, 1999.

[33] F. Huerta, S. Cobreces, F. Rodriguez, D. Pizarro, and F. Meca, "Blackbox identification for an auto-tuned current controller working with voltage source converters connected to the grid through a LCL filter," in Proc. IEEE ISIE, Bari, Italy, July 2010, pp. 96-101.

[34] F. Huerta, S. Cobreces, F. Rodriguez, C. Clancey, and I. Sanz, "Comparison of two black-box model identification methods applied on a VSC with LCL filter," in Proc. IEEE IECON, Montreal, Canada, Oct. 2012, pp. 4648-4653

[35] T. Roinila, T. Messo, and E. Santi, "MIMO-identification techniques for rapid impedance-based stability assessment of three phase systems in DQ domain," IEEE Trans. Power Electron., 2017, early access.

[36] J. Koppinen, J. Kukkola, and M. Hinkkanen, "Parameter estimation of an LCL filter for control of grid converters," in Proc. ICPE-ECCE Asia, Seoul, South Korea, June 2015, pp. 1260 - 1267.

[37] T. Söderström and P. Stoica, System Identification. UK: Prentice Hall International, 1989.

[38] J. Kukkola and M. Hinkkanen, "State observer for grid-voltage sensorless control of a converter equipped with an LCL filter: Direct discretetime design," IEEE Trans. Ind. Appl., vol. 52, no. 4, pp. 3133-3145, July/Aug. 2016.

[39] J. Schoukens, R. Pintelon, and H. van Hamme, "Identification of linear dynamic systems using piecewise constant excitations: use, misuse and alternatives," Automatica, vol. 30, no. 7, pp. 1153-1169, 1994.

[40] J. G. Proakis and D. G. Manolakis, Digital Signal Processing: Principles, Algorithms and Applications, 4th ed. Upper Saddle River, NJ: Pearson/Prentice Hall, 2007.

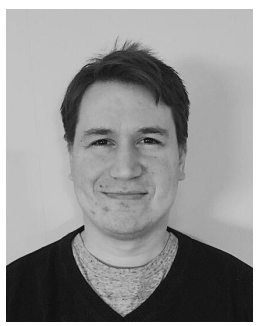

Jussi Koppinen received the B.Sc.(Tech.) and M.Sc.(Tech.) degrees in electrical engineering from the Aalto University, Espoo, Finland, in 2010 and 2013, respectively.

$\mathrm{He}$ is currently a doctoral candidate with the School of Electrical Engineering, Aalto University. His research interests include gridconnected converters.

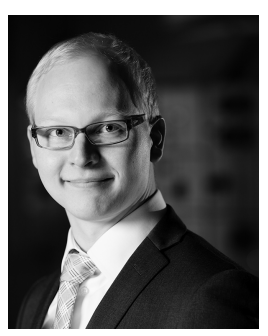

Jarno Kukkola received the B.Sc.(Tech.), M.Sc.(Tech.), and D.Sc.(Tech.) degrees in electrical engineering from the Aalto University, Espoo, Finland, in 2010, 2012, and 2017, respectively.

$\mathrm{He}$ is currently a Design Engineer with $\mathrm{ABB}$ Drives, Helsinki, Finland. His research interests include grid-connected converters.

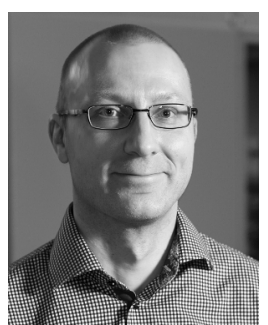

Marko Hinkkanen (M'06-SM'13) received the M.Sc.(Eng.) and D.Sc.(Tech.) degrees in electrical engineering from the Helsinki University of Technology, Espoo, Finland, in 2000 and 2004, respectively.

$\mathrm{He}$ is an Associate Professor with the School of Electrical Engineering, Aalto University, Espoo. His research interests include control systems, electric drives, and power converters.

Dr. Hinkkanen was the corecipient of the 2016 International Conference on Electrical Machines (ICEM) Brian J. Chalmers Best Paper Award and the 2016 IEEE Industry Applications Society Industrial Drives Committee Best Paper Award. He is an Editorial Board Member of IET Electric Power Applications. 